\title{
Do we know everything about vaccines and COVID-19?
}

\author{
Luis Villela ${ }^{1 *}$, Fidel Valle ${ }^{1}$, and Vittorio García-Zamudio ${ }^{2}$ \\ ${ }^{1}$ Hematology Service, Hospital Ocaranza, Instituto de Seguridad y Servicios Sociales de los Trabajadores del Estado (ISSSTE); ${ }^{2}$ Centro Ambulatorio \\ para la Prevención y Atención a VIH-SIDA e Infecciones de Transmisión Sexual, CAPASITS, Secretaria de Salud. Hermosillo, Sonora, Mexico
}

Undoubtedly, the current COVID-19 pandemic has made human beings place their trust in science, especially for the creation of vaccines that effectively prevent serious complications due to SARSCOV2 infection. One of the most important challenges was developing a vaccine that should be ready in record time due to the contagion capacity of the SARSCOV2 virus. By the end of December 2020, several vaccine candidates and different platforms, such as an inactivated virus, a live-attenuated virus, a protein subunit virus, and particle (VLP, DNA, RNA) and viral vectored vaccines, were reported to the WHO for the vaccine design ${ }^{1}$, where the main target has been the Spike (S) protein that binds to the angiotensin-converting enzyme receptor 2 (ACE2). However, in phase 3 and in open use, these vaccines only recognize the WHO 3 platforms: mRNA, viral vector, and inactivated virus vaccines ${ }^{1}$. Furthermore, one of the cornerstones for the management of patients with SARS-COV2 is anticoagulation with low molecular weight heparin, good management of oxygenation/pronation of patients and other concomitant therapies, such as steroids and antivirals such as remdesivir .

With the rapidity that vaccines were developed and used, we knew little of the medium and long-term complications they could present. Among them, a phenomenon of thrombocytopenia/thrombosis has been reported with different types of immunological vaccines ${ }^{2,3}$. The sites that have been reported are cerebral venous thrombosis, splanchnic-vein thrombosis, and pulmonary embolism.

It is very interesting that the immunological phenomena in SARS-COV2 infection were already being reported at the beginning of the pandemic (April 2020). These immunological phenomena can be associated with paradoxical phenomena of thrombocytopenia/thrombosis, such as antiphospholipid antibodies ${ }^{4}$.

Some reviews are available on this rare complication. In this issue of the Medicina Universitaria journal, Irabien-Zúñiga et al. present a comprehensive review on vaccine-induced immune thrombotic thrombocytopenia syndrome $(\mathrm{VITT})^{5}$. The authors carry out an extensive review of the basics such as the definition of thrombocytopenia and associated thrombosis and what is heparin-associated thrombocytopenia (HIT), the types of thrombosis associated with vaccines against COVID-19, diagnostic approach, resources, and treatment modalities.

Furthermore, it makes us ask ourselves what we really know about COVID and its variants? Do we know their link between the virus proteins and the cross-over phenomena of thrombocytopenia and thrombosis? What are the risks/benefits of preventive therapies used "prematurely" in the face of the pandemic era? Would all this enter a philosophical, ethical discussion?

Finally, we believe that it is necessary to continue applying the vaccine, monitor the population, look for 
new monitoring methods for VITT, determine population risk characteristics, and evaluate which vaccines are the least associated with these rare phenomena and serious complications.

\section{References}

1. Chung JY, Thone MN, Kwon YJ. COVID-19 vaccines: the status and perspectives in delivery points of view. Adv Drug Deliv Rev. 2021;170:1-25.
2. Greinacher A, Thiele T, Warkentin TE, Weisser K, Kyrle PA, Eichinger S. Thrombotic thrombocytopenia after ChAdOx1 nCov-19 vaccination. N Engl J Med. 2021;384:2092-101.

3. Dias L, Soares-Dos-Reis R, Meira J, Ferrão D, Soares PR, Pastor A, et al. Cerebral venous thrombosis after bnt162b2 mRNA SARS-CoV-2 vaccine. J Stroke Cerebrovasc Dis. 2021;30:105906.

4. Zhang Y, Xiao M, Zhang S, Xia P, Cao W, Jiang W, et al. Coagulopathy and antiphospholipid antibodies in patients with Covid-19. N Engl J Med. 2020;382:e38.

5. Irabien-Zúñiga M, Rojas Guerrero EA, Gómez-Almaguer D. Understanding Heparin-induced Thrombosis: A Brief Review. Medicina Universitaria. 2021;23(3):103-6. 